\title{
Accounting for Unexpected Capital Gains on Natural Assets in Net National Product
}

\author{
(C) Robert J. Hill \\ School of Economics \\ University of New South Wales \\ Sydney 2052, Australia \\ E-Mail: r.hill@unsw.edu.au
}

February 10, 2003

Failure to separate unexpected capital gains and losses on natural assets from depletion breaks the link between Net National Product (NNP) and sustainability. In addition, for resource rich countries this can lead to large spurious fluctuations in NNP, making it virtually useless for policy purposes. In contrast, when depletion is measured correctly, the link between NNP and sustainability is restored and there is no reason to expect NNP to be any more volatile than GNP. Oil data for Great Britain and Indonesia are used to illustrate the very significant impact that the treatment of capital gains and depletion can have on NNP. (JEL O47, P44, Q32)

KEY WORDS: Capital Gains; Depletion; Income; Net National Product; Environmental Accounting; Sustainability

Paper to be presented at the Economics and Environment Network National Workshop, May 2-3, 2003, at the Australian National University. 


\section{Introduction}

Interest in the measurement of depletion, capital gains and the sustainability of growth has been stimulated by the 1992 United Nations Conference on Environment and Development in Rio de Janeiro, and the publication in 1993 of the new internationally agreed System of National Accounts (SNA). ${ }^{1}$ The 1993 SNA has been criticized, however, by environmental groups for its failure to record the depletion of natural assets, such as mineral deposits or oil fields, in the production account and recognize it as a cost of production. ${ }^{2}$ The values of the natural assets extracted form part of the values of the outputs of mining or oil companies, and hence are included in full in Gross National Product (GNP), but no charge is made for the using up of the assets which are not reproducible and not inexhaustible. Environmentalists, such as Repetto (1992), argue that the UN, World Bank and IMF are, therefore, indirectly encouraging countries to follow unsustainable paths of development because frequently the fastest way to increase real GNP in the short-run is to deplete the natural capital stock. Many developing countries seem to have followed such economic policies even though the growth rate of real GNP may be unsustainable in the longer run and provide a potentially highly misleading indicator of economic performance.

Net National Product (NNP) is defined in the SNA as GNP less the depreciation on produced assets, such as machinery and buildings (or consumption of fixed capital as it is called in the SNA). Although NNP provides a better indicator of economic performance it still fails to take account of the depletion of natural assets. Hence, Repetto (1992) and Pearce and Atkinson (1995) argue that NNP should be redefined by

\footnotetext{
${ }^{1}$ The 1993 SNA was published jointly by the United Nations, World Bank, IMF, OECD and the European Community. It has been adopted by all the major countries in the world, including China, Russia and the USA, and provides the conceptual framework for all macroeconomic data used for analytic and policy purposes.

${ }^{2}$ Actually, depletion of natural capital is included in the 1993 SNA, but in the wrong place. It is recorded as an adjustment item to reconcile the values of stocks of natural assets in the opening and closing balance sheets but not in the production account.
} 
deducting depletion as well as depreciation from GNP, a proposal that has the support of many national accountants also. The depreciation of produced assets and the depletion of natural assets have much in common conceptually and both need to be deducted when measuring the net value added created by production. In the rest of this paper we adopt this extended definition of NNP. ${ }^{3}$ As environmentalists argue, it provides a better indicator of economic performance and its adoption would encourage countries to follow more sustainable policies. Under certain conditions, NNP can be interpreted as the maximum level of consumption that would permit the overall capital stock (i.e., both produced and natural capital) to be maintained intact. ${ }^{4}$ Therefore, barring unexpected capital losses such as those due to natural disasters and assuming a nondecreasing real interest rate, a level of consumption equal to NNP could be maintained indefinitely. ${ }^{5}$ Hence NNP is much more closely linked than GNP to the concept of sustainability. A rise in a country's per capita real NNP should constitute sustainable development. ${ }^{6}$

In practice, both depreciation and depletion, and hence NNP, are difficult to measure, since they require estimates of changes in the values of capital assets. This largely explains the widespread use of GNP as an indicator of economic performance, despite its conceptual inadequacies. Frequently, insufficient data are available to estimate depreciation and depletion. Even when data are available, estimates of the depletion of natural assets are liable to be distorted by capital gains (losses). ${ }^{7}$

\footnotetext{
${ }^{3}$ This environmentally adjusted version of NNP is also sometimes referred to as ENP in the environmental accounting literature [see, for example, Bartelmus, Stahmer and van Tongeren (1993)].

${ }^{4}$ Strictly speaking this is only true if the relative price of consumption and investment goods is independent of the level of consumption, an assumption that is not that unreasonable for small open economies [see Weitzman (1976)].

${ }^{5}$ The impact of decreasing real interest rates on the maximum sustainable level of consumption and NNP is explored by Asheim (1997).

${ }^{6}$ This is not to say that a constant level of consumption over time is actually optimal. In general, unless society has maximin (or Rawlsian) preferences across generations, it will not be. The implications of maximin preferences for the use of nonrenewable resources is explored in Solow (1974).

${ }^{7}$ Partly for these reasons, depletion was excluded from the production account of the SNA. There was concern that its inclusion might undermine the integrity of the rest of the system, [see for example
} 
The treatment of capital gains on natural assets in the national accounts has been discussed by, amongst others, Mäler (1991), Asheim (1996), and Vincent, Panayotou and Hartwick (1997). The general consensus that emerges from this literature is that all capital gains arising from discoveries of new stocks of natural assets or changes in the price of these stocks should be included in NNP. However, there is some controversy over the treatment of capital gains arising from changes in the interest rate. This controversy is discussed in the next section. More important in the context of this paper is the fact that, by assuming a perfect foresight setting, these authors completely ignore the treatment of unexpected capital gains.

This paper focuses on unexpected capital gains on natural assets and their implications for NNP. ${ }^{8}$ The main sources of unexpected capital gains on natural capital are changes in commodity prices and discoveries of new stock. Most empirical studies thus far [see for example Repetto et al. (1989) for Indonesia and Young (1993) for Australia] have included unexpected capital gains in NNP. As a result, the NNP series obtained by these authors are highly erratic. This is because the magnitude of the unexpected capital gains (losses) on natural capital can be huge for resource rich countries. A case in point is Norway. In some years, changes in the total value of Norway's stock of oil, due to price changes, have exceeded its GNP [see Aslaksen et al. (1990) and Aaheim and Nyborg (1995)]. By implication, in the mid-1980s when the price of oil collapsed, Norway's NNP would have gone negative if all capital gains (losses) on natural capital were included in NNP. Clearly, failure to separate unexpected capital gains from depletion may introduce spurious volatility into measured NNP, particularly for resource rich countries, thereby undermining its credibility as an indicator of economic performance.

El Serafy (1989) and Hartwick and Hageman (1993) address the problem of how to adjust NNP for discoveries of new stock. The methods proposed in these papers dampen Thage (1991)]. Instead, separate "satellite" environmental accounts have been proposed [see Bartelmus, Stahmer and van Tongeren (1993)].

${ }^{8}$ In a related paper, Hill and Hill (2003) consider the implications for NNP of the treatment of other types of assets, as well as exploring more generally the link between income and capital gains. 
somewhat the impact of discoveries on NNP, as does the method recommended here. Hartwick and Hageman also discuss briefly the treatment of unexpected price changes. Their position on this issue is consistent with our approach. Both the El Serafy (1989) and Hartwick and Hageman (1993) papers are discussed in greater detail later.

It is argued here that the correct treatment of capital gains in NNP hinges on the definition of depletion. Hotelling (1925) developed the economic theory underlying the concepts of depreciation and depletion. The concept of income, as discussed by Hicks (1946), is closely related. It is due to a persistent misinterpretation of both concepts that most empirical studies fail to separate unexpected capital gains from depletion so that measured depletion is often a confused mixture of the two. Lumping unexpected capital gains in with depletion has two disadvantages. First, it breaks the link between NNP and sustainability. The winner of a lottery (e.g., a country with large oil reserves when the price of oil rises) cannot expect to maintain a level of consumption equal to this lottery win period after period into the future. Second, it may cause measured NNP to become highly erratic. However, when the Hotelling concept of depletion is correctly implemented and unexpected capital gains are excluded (except for the interest earned on these gains), the link between NNP and sustainability is restored. Furthermore, it is shown that there is no reason to expect NNP to be any more volatile than GNP. Therefore, by treating unexpected capital gains correctly, the main obstacles to widespread use of NNP as a guide to government policy (i.e., the lack of a link to sustainability, and excessive volatility) are removed.

Illustrative applications of the theoretical model developed in this paper are provided using British and Indonesian oil data. The application using British data focuses on the impact of North Sea Oil on GNP and NNP between 1976 and 1995, while the Indonesian application replicates Repetto et al.'s (1989) study. In both cases, it is shown that the volatility of NNP may be dramatically reduced when unexpected capital gains are excluded from depletion. 


\section{Some Conceptual Issues}

\section{(i) Valuing Assets}

Throughout this paper, all prices and values are measured in constant dollars. Also, all prices and the interest rate are treated as exogenous. In this sense, the analysis is directed primarily towards small open economies.

Consider a stock of assets at the beginning of period $t . R_{t, t+k+i}$ denotes the receipt earned from this stock of assets in period $t+k+i$ assuming that none of the receipts earned between periods $t$ and $t+k+i$ are reinvested in the stock of assets. $V_{t, t+k}$ denotes the value of the stock of assets existing at the beginning of period $t$ at a later date $t+k$ assuming that none of the receipts earned between periods $t$ and $t+k$ are reinvested. $V_{t, t+k}$ is equal to the discounted stream of future receipts, $R_{t, t+k+i}$, from period $t+k$ onwards: ${ }^{9}$

$$
V_{t, t+k} \equiv \sum_{i=0}^{\infty}\left[\prod_{j=0}^{i}\left(\frac{1}{1+r_{t+k+j}}\right) R_{t, t+k+i}\right],
$$

where $r_{t}$ is the real interest rate in period $t$. If the formula for $V_{t, t+k}$ in (1) is written out in full for the cases where $k=0$ and $k=1$, it can be seen that $V_{t t}$ and $V_{t, t+1}$ are related as follows:

$$
V_{t, t+1}=\left(1+r_{t}\right) V_{t t}-R_{t t}
$$

The value of the actual stock of assets at the start of period $t+k$, namely, $V_{t+k, t+k}$ will not be the same as $V_{t, t+k}$ when some of the receipts earned between periods $t$ and $t+k$ are reinvested, or if some of the assets are sold. For the case where $k=1$, the amount of this investment is determined by the difference between receipts $R_{t t}$ and consumption $C_{t}$ in period $t$. Thus,

$$
V_{t+1, t+1}=V_{t, t+1}+R_{t t}-C_{t}
$$

$\left(R_{t t}-C_{t}\right)$ being the amount reinvested. Combining (2) and (3), it follows that

$$
V_{t+1, t+1}=\left(1+r_{t}\right) V_{t t}-C_{t} .
$$

\footnotetext{
${ }^{9}$ It should be noted that whether or not receipts are reinvested from period $t+k$ onwards has no effect on $V_{t, t+k}$.
} 
To simplify the notation for the remainder of the paper, in cases where $k=0$, we will write $V_{t}$ and $R_{t}$, respectively, in place of $V_{t t}$ and $R_{t t}$. Using this notation, rearranging $(2)$, it follows that

$$
r_{t} V_{t}=R_{t}+V_{t, t+1}-V_{t}
$$

Similarly, rearranging (4), it follows that

$$
r_{t} V_{t}=C_{t}+V_{t+1}-V_{t}
$$

As is shown below, these two expressions for the interest earned on a stock of assets play an important role in the measurement of income.

\section{(ii) Income Under Perfect Foresight}

The main purpose of income is to provide guidance to households or other economic units, including government, on the rate at which they can afford to consume when there is uncertainty about future resources. As a point of departure, consider the widely quoted definition of income given in Hicks's Value and Capital:

$[D]$ efine a man's income as the maximum value that he can consume during a week, and still expect to be as well off at the end of the week as he was at the beginning. [Hicks (1946), Second Edition, p. 172]

This definition is not sufficiently precise as it stands. It nests two income concepts that Hicks referred to as income no. 1 and no. 2. Hicksian income no. 1 is the maximum level of consumption that will maintain wealth intact, while Hicksian income no. 2 is the maximum sustainable level of consumption. These two concepts coincide only when the interest rate remains fixed over time [see Hicks (1946), pp. 173-4].

More formally, Hicksian income no. 1, denoted here by $Y_{t}$, is defined as follows:

$$
Y_{t} \equiv \operatorname{Max}\left\{C_{t}: V_{t+1} \geq V_{t}\right\}
$$

Setting $V_{t+1}=V_{t}$ in (6), it follows from (7) that

$$
Y_{t}=r_{t} V_{t}
$$


Substituting (5) and (6) into (8), it can be seen that Hicksian income no. 1 can also be written as follows:

$$
Y_{t}=R_{t}+V_{t, t+1}-V_{t}=C_{t}+V_{t+1}-V_{t}
$$

Hicksian income no. 1 , therefore, is equal to total receipts $R_{t}$ plus $\left(V_{t, t+1}-V_{t}\right)$, the total capital gains on the stock of assets existing at the beginning of the period. Equation (9) also shows that income is equal to consumption $C_{t}$ plus $\left(V_{t+1}-V_{t}\right)$, the actual change in the value of the stock of assets. The latter reflects the effects of investment or disinvestment as well as capital gains. This change can be decomposed into the capital gain on the stock held at the start of the period, $\left(V_{t, t+1}-V_{t}\right)$, and net investment during the period, $\left(V_{t+1}-V_{t, t+1}\right)$.

By contrast, Hicksian income no. 2, denoted by $\hat{Y}_{t}$, is defined as follows:

$$
\hat{Y}_{t} \equiv \operatorname{Max}\left\{C_{t}: \sum_{i=0}^{\infty}\left[\prod_{j=0}^{i}\left(\frac{1}{1+r_{t+j}}\right) C_{t}\right] \leq V_{t}\right\}
$$

which reduces to

$$
\hat{Y}_{t}=V_{t} / \sum_{i=1}^{\infty}\left[\prod_{j=0}^{i}\left(\frac{1}{1+r_{t+j}}\right)\right] .
$$

$\hat{Y}_{t}$ excludes part of the capital gain (loss) arising from interest rate changes. Hicks's two concepts of income are equivalent only when the interest rate does not change over time. In this case, both $Y_{t}$ and $\hat{Y}_{t}$ reduce to $r V_{t}$. A rate of consumption equal to $r V_{t}$ maintains wealth intact and is sustainable indefinitely if $r$ does not change. ${ }^{10}$

\footnotetext{
${ }^{10}$ Equation (9) shows that if there is no capital gain, Hicksian income no. 1 equals consumption plus net investment. Weitzman's (1976) seminal paper on national accounting showed that, under the assumption of a constant interest rate in an economy with a single consumption and investment good, national income, defined as the sum of consumption and net investment, can be interpreted as a measure of welfare. In our context, what is interesting is the absence of capital gains in Weitzman's welfare measure. A natural way of incorporating capital gains into Weitzman's model is by assuming that the price of capital changes over time in a specified way (as for example might be the case for an open economy exporting a non-renewable natural resource whose price follows the Hotelling rule) rather than being determined endogenously. In this case, the price of capital itself becomes a state variable in the Hamiltonian, and hence the resulting capital gains are part of income (and welfare).
} 


\section{(iii) Income Under Uncertainty}

Further complications arise when we allow for uncertainty. Here we will consider generalizations under uncertainty of Hicksian income no. 1, since it is the simpler concept. It is worth emphasizing at this point that the choice between Hicksian income no. 1 and no. 2 does not affect the substance of this paper which focuses on the treatment of unexpected capital gains. Furthermore, in sections 3, 4 and 5 it is assumed that the interest rate does not vary over time. Under this assumption, as noted earlier, both income concepts are the same. The concept of the maximum sustainable level of consumption (i.e., Hicksian income no. 2) will be appealed to frequently in these sections.

When there is uncertainty the estimated value of a person's wealth at any point of time depends on the time at which the estimate is made. Define $E_{s} V_{t}$ as the expectation at time $s$ of the value of the stock of assets existing at the beginning of period $t$. Time $s$ can precede, coincide with or follow $t$. Since the stream of receipts $\left(R_{s}, R_{s+1}, R_{s+2}, \ldots\right)$ can extend indefinitely into the future, this implies that $V_{t}$, in general, is never known for certain, even if $s>t$.

\section{Haig-Simons Income}

The Haig (1921)-Simons (1938) definition of income is widely used by economists [see, for example, McElroy (1976) and Eisner (1988, 1990)]. It is an ex post version of Hicksian income no. 1. Haig-Simons income, denoted here by $Y_{t}^{H S}$, is defined as follows:

$$
Y_{t}^{H S} \equiv \operatorname{Max}\left\{C_{t}: E_{t+1} V_{t+1} \geq E_{t} V_{t}\right\}
$$

Hill and Hill (2003) show that Haig-Simons income can be rewritten as follows:

$$
Y_{t}^{H S}=C_{t}+E_{t+1} V_{t+1}-E_{t} V_{t}=R_{t}+E_{t+1} V_{t, t+1}-E_{t} V_{t}
$$

In other words, Haig-Simons income can be expressed as the sum of consumption plus the actual change in wealth over the period, or as the sum of receipts and the actual change in the value of the stock of assets existing at the start of the period. 
Haig-Simons income equals the amount a person can consume in period $t$ and be as well off at the beginning of period $t+1$ as he thought he was at the beginning of period $t$. The basic flaw in the concept is that a prudent consumer has no reason to wish to preserve $E_{t} V_{t}$ intact as soon as events have shown it to be wrong.

Suppose the price of oil rises unexpectedly in period $t$. Assuming this price rise is perceived as permanent, Haig-Simons includes the whole increase in the value of oil reserves in income for period $t$. If households and the government in an oil rich country use the Haig-Simons definition of income to guide their consumption decisions, they would be encouraged to spend the whole windfall in the current period in order to return wealth to its initial level. Clearly this level of consumption could not be maintained indefinitely into the future and hence is not sustainable. Haig-Simons breaks the link between income and sustainability, since sustainability is a forward looking concept while Haig-Simons is backward looking. In addition, such a consumption strategy would be quite arbitrary as it would make the rate of consumption depend on the length of the accounting period (of whose existence households and government may not even be aware).

\section{Generalized-Hicksian Income}

None of the objections just raised to the Haig-Simons concept of income apply to the 'generalized-Hicksian' income concept defined in Hill and Hill (2003). GeneralizedHicksian income estimates wealth consistently at both the beginning and the end of the period on the basis of the same information and expectations. The expectation at time $s$ of income in period $t$ is

$$
E_{s} Y_{t} \equiv \operatorname{Max}\left\{E_{s} C_{t}: E_{s} V_{t+1} \geq E_{s} V_{t}\right\}
$$

Hill and Hill (2003) show that $E_{s} Y_{t}$ can be rewritten as follows:

$$
E_{s} Y_{t}=E_{s} R_{t}+E_{s} V_{t, t+1}-E_{s} V_{t}=E_{s} C_{t}+E_{s} V_{t+1}-E_{s} V_{t}
$$

It should be noted that $R_{t}$ and $C_{t}$ in (14) are known if $s>t$. Income as defined in (13) 
depends on the time, $s$, at which it is estimated. Two cases of particular interest are the start and the end of the accounting period. When $s=t, E_{t} Y_{t}$ is the ex ante definition of income discussed in Hicks (1946, p. 172). Also, it is worth noting that Friedman's (1957) concept of permanent income is essentially the same as ex ante Hicksian income [see Eisner (1990, p. 1180)].

$$
E_{t} Y_{t}=\operatorname{Max}\left\{C_{t}: E_{t} V_{t+1} \geq E_{t} V_{t}\right\}
$$

so that

$$
E_{t} Y_{t}=E_{t}\left(r_{t} V_{t}\right)=E_{t} R_{t}+\left(E_{t} V_{t, t+1}-E_{t} V_{t}\right)=E_{t} C_{t}+\left(E_{t} V_{t+1}-E_{t} V_{t}\right) .
$$

Ex ante income, $E_{t} Y_{t}$, is the maximum amount that a person can plan to consume in period $t$ and expect wealth at the end of the period to be the same as estimated at the start of the period. Hicks argues that this is the concept of income relevant to consumer behavior, as does Friedman (1957) in his permanent income hypothesis.

The problem with $E_{t} Y_{t}$ is that it can be computed at the beginning of period $t$ and hence is only a forecast. For this reason, the corresponding ex post concept of income obtained by setting $s=t+1$ is preferable in an accounting context.

$$
E_{t+1} Y_{t}=\operatorname{Max}\left\{C_{t}: E_{t+1} V_{t+1} \geq E_{t+1} V_{t}\right\}
$$

so that

$$
E_{t+1} Y_{t}=r_{t}\left(E_{t+1} V_{t}\right)=R_{t}+\left(E_{t+1} V_{t, t+1}-E_{t+1} V_{t}\right)=C_{t}+\left(E_{t+1} V_{t+1}-E_{t+1} V_{t}\right)
$$

Hartwick and Hageman (1993) also advocate using an ex post income concept of this type to deal with unexpected capital gains, particularly those caused by price shocks.

If one is analyzing data from the past that feature a structural break because of a then-unanticipated shock, one might use post-discovery prices in the prediscovery periods near the date of the unanticipated discovery or shock to smooth out calculations of true economic depreciation or to obtain more accurate benefit-cost estimates. [Hartwick and Hageman (1993, p. 228)] 
It must be emphasized that measuring income ex post does not mean that all uncertainty has been resolved but simply that measurement takes place after the end of the period when actual receipts and consumption in period $t$ are known. Ex post income is still a forward looking measure. It depends on expectations of future receipts held at the end of the period. It should also be emphasized that ex post income, as defined in (17) and (18), is not the income concept labelled as ex post by Hicks in Value and Capital. Hicks chose to identify ex post income with Haig-Simons, which he dismissed on the grounds that it must contain unexpected capital gains whereas "The income which is relevant to conduct must always exclude windfall gains" [Hicks (1946), p. 179]. It is shown below that, unlike Haig-Simons income, ex post income excludes unexpected capital gains.

\section{(iv) Capital Gains}

Following Hill and Hill (2003), the capital gain on a given stock of assets is defined as the change in its value between two points of time. $G_{(t, t+k)}$ is used to denote the capital gain accruing between the start of period $t$ and the start of period $t+k$ on the stock existing at the start of period $t$.

$$
G_{(t, t+k)} \equiv E_{t+k} V_{t, t+k}-E_{t} V_{t}
$$

Defined this way, capital gains can be divided into expected and unexpected components. The expected capital gain accruing between the start of period $t$ and $t+k$, based on expectations at time $s$, is

$$
E_{s} G_{(t, t+k)} \equiv E_{s} V_{t, t+k}-E_{s} V_{t}
$$

An unexpected capital gain, denoted here by $U G$, occurs when the estimated value of the stock of assets at some point of time is changed as a result of revised expectations. The unexpected capital gain on the stock at time $t$ resulting from new information gained during the time interval $(h, l)$, where $h \leq l$, is defined as follows:

$$
U_{(h, l)} G_{t} \equiv E_{l} V_{t}-E_{h} V_{t}
$$


Of particular interest are the cases where $s=t$ or $s=t+k$ in (20), and $h=t$ and $l=t+k$ in $(21)$. For these cases, it is possible to decompose a capital gain into its expected and unexpected components (in two different ways).

$$
G_{(t, t+k)}=E_{t} G_{(t, t+k)}+U_{(t, t+k)} G_{(t+k)}=E_{t+k} G_{(t, t+k)}+U_{(t, t+k)} G_{t}
$$

It can now be seen that Haig-Simons income can be written as the sum of receipts and capital gains, i.e.:

$$
Y_{t}^{H S}=R_{t}+E_{t+1} V_{t, t+1}-E_{t} V_{t}=R_{t}+G_{(t, t+1)} .
$$

Similarly, generalized-Hicksian income can be written as the sum of expected receipts and expected capital gains, i.e.:

$$
E_{s} Y_{t}=E_{s} R_{t}+E_{s} V_{t, t+1}-E_{s} V_{t}=E_{s} R_{t}+E_{s} G_{(t, t+1)} .
$$

This in turn implies that ex post income and Haig-Simons income are related as follows:

$$
\begin{gathered}
Y_{t}^{H S}=R_{t}+E_{t+1} V_{t, t+1}-E_{t} V_{t}=\left(R_{t}+E_{t+1} V_{t, t+1}-E_{t+1} V_{t}\right) \\
+\left(E_{t+1} V_{t}-E_{t} V_{t}\right)=E_{t+1} Y_{t}+U_{(t, t+1)} G_{t} .
\end{gathered}
$$

Haig-Simons income is equal to ex post income plus the unexpected capital gain or loss in period $t$ resulting from new information that emerged during period $t .^{11}$

\section{(v) Depletion of Natural Assets}

Following Hotelling (1925), and assuming perfect foresight, the depletion of a natural asset such as an oil field during period $t$ is defined as the decrease in its value between the beginning and end of the period. Alternatively, depletion can be thought of as that part of receipts that are not income [see El Serafy (1989)]. These two definitions are equivalent. Although straightforward under perfect foresight, the concept of depletion

\footnotetext{
${ }^{11}$ It should be noted that although ex post income, $E_{t+1} Y_{t}$, excludes unexpected capital gains in period $t$, the interest earned on these gains, $r_{t} U_{(t, t+1)} G_{t}$, is included in ex post income. This point is made clear in equation (37).
} 
becomes more complex when one allows for uncertainty. In fact, each concept of income has its own corresponding definition of depletion. The concept of depletion consistent with Haig-Simons income is denoted here by $D_{t}^{H S}$.

$$
D_{t}^{H S}=E_{t} V_{t}-E_{t+1} V_{t+1}
$$

Comparing (26) with (19) shows that $D_{t}^{H S}=-G_{(t, t+1)}$. In other words, Haig-Simons depletion equals the total capital loss in period $t$. Haig-Simons income and depletion are related as follows:

$$
Y_{t}^{H S}=R_{t}-\left(E_{t} V_{t}-E_{t+1} V_{t+1}\right)=R_{t}-D_{t}^{H S}
$$

The concept of depletion consistent with generalized-Hicksian income is denoted here by $E_{s} D_{t}$. We will refer to the cases where $s=t$ and $s=t+1$ here as ex ante and ex post depletion, respectively.

$$
E_{s} D_{t}=E_{s} V_{t}-E_{s} V_{t+1}
$$

Generalized-Hicksian income and depletion are related as follows:

$$
E_{s} Y_{t}=E_{s} R_{t}-\left(E_{s} V_{t}-E_{s} V_{t+1}\right)=E_{s} R_{t}-E_{s} D_{t}
$$

Comparing (28) with (20) shows that $E_{s} D_{t}=-E_{s} G_{(t, t+1)}$. Returning to the example of an oil field, this result implies that generalized-Hicksian depletion will be unaffected by unexpected changes in the price of oil.

The relationship between Haig-Simons depletion and ex post depletion is given below in (30). Since depletion is defined as a decrease in the value of an asset over time, it is convenient (following Hotelling) to multiply through by minus 1 in order to reverse the signs in (30).

$$
\begin{gathered}
-D_{t}^{H S}=E_{t+1} V_{t+1}-E_{t} V_{t}=\left(E_{t+1} V_{t+1}-E_{t+1} V_{t}\right)-\left(E_{t} V_{t}-E_{t+1} V_{t}\right) \\
=-E_{t+1} D_{t}+U_{(t, t+1)} G_{t}
\end{gathered}
$$


Hence ex post depletion excludes unexpected capital gains or losses, whereas the HaigSimons definition includes them.

At this point it is also useful to discuss briefly two other depletion formulae that have received attention in the environmental accounting literature. The first, proposed by El Serafy (1989), assumes constant receipts for a finite number of periods (say $T$ ) after which the resource is exhausted. Given this assumption, it follows that for $1 \leq t \leq T$ :

$$
V_{t}=\frac{R}{1+r}+\frac{R}{(1+r)^{2}}+\cdots+\frac{R}{(1+r)^{T+1-t}}=\frac{R}{r}\left[1-\left(\frac{1}{1+r}\right)^{T+1-t}\right],
$$

which in turn implies that

$$
D_{t}=V_{t}-V_{t+1}=\frac{R}{(1+r)^{T+1-t}}
$$

El Serafy also discusses how this formula can be adjusted to take account of discoveries of new stock. He argues that discoveries should be viewed as simply increasing the number of periods over which constant receipts are paid. For example, suppose enough barrels of oil are discovered in period $t$ to allow the current rate of extraction to be maintained for $X$ more periods than previously anticipated. Then recorded depletion in period $t$ will be $R /(1+r)^{T+X+1-t}$, which is less than $R /(1+r)^{T+1-t}$ (i.e., the discovery causes measured depletion to fall). Unexpected price shocks, meanwhile, can be viewed as changing $R$. For example, suppose the price of oil rises in period $t$. For an oil-rich country, assuming the rate of extraction does not fall in response to the price rise, this means $R_{t}>R_{t-1}$. Hence depletion in period $t$ will be $R_{t} /(1+r)^{T+1-t}$, which is greater than $R_{t-1} /(1+r)^{T+1-t}$. In other words, rather than observing a large negative spike, recorded depletion actually rises in an oil-rich country when the price of oil rises. ${ }^{12}$ This is because the extracted oil is now more valuable.

The second alternative depletion formula is the total Hotelling rent formula proposed by Hartwick (1989). Under the assumption that marginal receipts rise at the rate of interest over time [i.e., the Hotelling (1931) rule], depletion equals total Hotelling rent

\footnotetext{
${ }^{12}$ The same pattern is observed for ex post Hicksian income, as is discussed later in the paper.
} 
which is the product of marginal receipts and the quantity extracted (i.e., for a price taking firm $\left.D_{t}=\left[P_{t}-M C_{t}(Q)\right] Q_{t}\right) .{ }^{13}$ In the presence of discoveries, Hartwick and Hageman (1993) show that the formula for total Hotelling rent (i.e., depletion) should be modified as follows:

$$
D_{t}=\left(P_{t}-M C_{t}(Q)\right) Q_{t}-M C_{t}(Z) Z_{t}
$$

where $Z_{t}$ denotes the quantity of the resource discovered in period $t$. In an example in their paper, Hartwick and Hageman handle price shocks by using the average of the prices prevailing at the beginning and end of the period, although at another point in the same paper they advocate using only ex post prices after a shock (see earlier quote).

We conclude this section with an informal comparison of the impact of discoveries of new stocks of nonrenewable resources on each of the depletion formulae discussed here. In the next section, a more detailed comparison is made between ex post Hicksian income and Haig-Simons income.

Suppose a new stock of an exhaustible resource is discovered during period $t$. How is each measure of depletion affected? Haig-Simons depletion, $D_{t}^{H S}$, is reduced by the full value of the discovery, which in some cases may cause depletion to become negative. Ex ante depletion, $E_{t} D_{t}$, is unaffected by the discovery since it occurs after the beginning of the period. Assuming receipts in period $t$ are unaffected by the discovery, ex post depletion, $E_{t+1} D_{t}$, will fall since GNP is unaffected, while NNP rises. However, ex post depletion falls much less than Haig-Simons depletion. Depletion, measured using El Serafy's formula, will also fall by a relatively small amount, and by construction cannot go negative. Finally, depletion measured using Hartwick and Hageman's formula also falls, although the magnitude of the fall will depend on the relative size of the marginal cost of discovery, $M C_{t}(Z)$, and the marginal cost of extraction, $M C_{t}(Q)$. If $M C_{t}(Z)$ is significantly less than $M C_{t}(Q)$, as it is in the example in Hartwick and Hageman (1993,

\footnotetext{
${ }^{13}$ The assumption that marginal receipts rise at the rate of interest over time, makes it possible to measure depletion without ever valuing the resource stock in a particular period.
} 
p. 226), then the fall in depletion will be considerably smaller than that observed using Haig-Simons depletion. In other words, the depletion formulae of El Serafy and Hartwick and Hageman, like ex post income, also tend to dampen the impact of unexpected capital gains on depletion and NNP.

\section{The Impact of Unexpected Capital Gains on Depletion, NNP and GNP}

The two main sources of unexpected capital gains on nonrenewable natural resource assets, such as oil, are changes in price and the discovery of new deposits. ${ }^{14}$ Technological progress and changes in the interest rate also generate capital gains. The implications of technological progress and changes in the interest rate for sustainability are discussed in Weitzman (1997) and Asheim (1997).

Consider the impact on the GNP and NNP of an oil exporting country of an unexpected change in the price (or stock) of oil. If the shock occurs during period $t$, its impact on expectations of GNP in period $t$ is given by

$$
\Delta E_{t+1} G N P_{t}=G N P_{t}-E_{t} G N P_{t}=R_{t}-E_{t} R_{t}
$$

It is assumed in (31) that GNP in period $t, G N P_{t}$, is known with certainty after the end of period $t$.

Before turning to NNP it is first useful to look at depletion. To simplify the analysis, it will be assumed for the remainder of the paper that the real interest rate $r$ does not vary over time. ${ }^{15}$ Also, it is assumed that the oil is not sold in a futures market before it is extracted. Nor are receipts used to buy more oil. Given these constraints, the first subscript on $R$ and $V$ can be dispensed with (i.e., $V_{t, t+k}=V_{t+k}$ and $R_{t, t+k}=R_{t+k}{ }^{16}$

\footnotetext{
${ }^{14}$ Actually, the treatment of discoveries of new deposits is not clear-cut. Since new discoveries are a direct consequence of exploration activities, they could be classified as gross capital formation instead of as capital gains. This issue is discussed in greater detail in Nordhaus and Kokkelenberg (1999) and Hill and Hill (2003).

${ }^{15}$ As discussed earlier, under this assumption Hicksian income no. 1 and 2 are equivalent.

${ }^{16}$ This does not preclude some of the receipts being invested in the infrastructure of the oil field.
} 
The expected value of the country's stock of oil at the beginning of period $t$, based on expectations at time $s$, can be written as follows:

$$
E_{s} V_{t}=\sum_{i=0}^{\infty}\left[\left(\frac{1}{1+r}\right)^{i+1} E_{s} R_{t+i}\right]
$$

It now follows from (5), when suitably generalized to allow for uncertainty, that

$$
E_{t+1} V_{t+1}=(1+r) E_{t+1} V_{t}-R_{t}
$$

Therefore, using (28), ex post depletion of the stock of oil in period $t$ is

$$
E_{t+1} D_{t}=E_{t+1} V_{t}-E_{t+1} V_{t+1}=R_{t}-r E_{t+1} V_{t}
$$

Similarly, ex ante depletion in period $t$ is

$$
E_{t} D_{t}=E_{t} V_{t}-E_{t} V_{t+1}=E_{t} R_{t}-r E_{t} V_{t}
$$

Now let $\Delta E_{t+1} D_{t}$ denote the difference between ex post and ex ante depletion in period $t$.

$$
\begin{gathered}
\Delta E_{t+1} D_{t}=E_{t+1} D_{t}-E_{t} D_{t}=\left(R_{t}-r E_{t+1} V_{t}\right)-\left(E_{t} R_{t}-r E_{t} V_{t}\right) \\
=R_{t}-E_{t} R_{t}-r\left(E_{t+1} V_{t}-E_{t} V_{t}\right)
\end{gathered}
$$

Also, let $\Delta D_{t}^{H S}$ denote the difference between Haig-Simons and ex ante depletion in period $t$.

$$
\begin{gathered}
\Delta D_{t}^{H S}=D_{t}^{H S}-E_{t} D_{t}=E_{t} V_{t}-E_{t+1} V_{t+1}-E_{t} R_{t}+r E_{t} V_{t} \\
=R_{t}-E_{t} R_{t}-(1+r)\left(E_{t+1} V_{t}-E_{t} V_{t}\right)
\end{gathered}
$$

$\Delta E_{t+1} D_{t}$ and $\Delta D_{t}^{H S}$ represent two different formulae for measuring the impact of an unexpected shock during period $t$ on depletion in period $t$. In particular, it should be noted that if nothing unexpected happens during period $t$, then $\Delta E_{t+1} D_{t}=\Delta D_{t}^{H S}=0$.

Each definition of depletion has its own corresponding definition of NNP. The definition consistent with the Haig-Simons concept of income, denoted here by $N N P_{t}^{H S}$, is given by

$$
N N P_{t}^{H S}=G N P_{t}-D_{t}^{H S}
$$


The generalized-Hicksian definition of NNP is given by

$$
E_{s} N N P_{t}=E_{s} G N P_{t}-E_{s} D_{t}
$$

A distinction can be drawn between ex ante NNP, $E_{t} N N P_{t}$, and ex post NNP, $E_{t+1} N N P_{t}$. Let $\Delta E_{t+1} N N P_{t}$ denote the difference between ex post and ex ante NNP in period $t$, as defined in (36).

$$
\begin{gathered}
\Delta E_{t+1} N N P_{t}=E_{t+1} N N P_{t}-E_{t} N N P_{t}=\left(G N P_{t}-E_{t+1} D_{t}\right)-\left(E_{t} G N P_{t}-E_{t} D_{t}\right) \\
=\Delta E_{t+1} G N P_{t}-\Delta E_{t+1} D_{t}=r\left(E_{t+1} V_{t}-E_{t} V_{t}\right)=r U_{(t, t+1)} G_{t}
\end{gathered}
$$

where $U_{(t, t+1)} G_{t}$ is the unexpected capital gain in period $t$ as defined in (21). In other words, unexpected capital gains in period $t$ are excluded from ex post NNP, although the income stream they generate, $r U_{(t, t+1)} G_{t}$, is included. In contrast, as shown below in (38), the Haig-Simons formula includes in NNP both unexpected capital gains in period $t$ and the income stream they generate.

$$
\begin{gathered}
\Delta N N P_{t}^{H S}=N N P_{t}^{H S}-E_{t} N N P_{t}=\left(G N P_{t}-D_{t}^{H S}\right)-\left(E_{t} G N P_{t}-E_{t} D_{t}\right) \\
=\Delta E_{t+1} G N P_{t}-\Delta D_{t}^{H S}=(1+r)\left(E_{t+1} V_{t}-E_{t} V_{t}\right)=(1+r) U_{(t, t+1)} G_{t}
\end{gathered}
$$

The $N N P_{t}^{H S}$ formula's treatment of unexpected capital gains is analogous to treating lottery winnings as income. As Hicks observed, this amounts to confusing the concepts of income and capital.

What can be deduced about the relative magnitudes of $\Delta E_{t+1} G N P_{t}, \Delta E_{t+1} N N P_{t}$ and $\triangle N N P_{t}^{H S}$ ? To answer this question we must impose some structure on expectations of future receipts. The approach followed here can be contrasted with that of El Serafy (1989). By assuming that the receipts generated each period are the same until the resource stock is exhausted, as discussed in the previous section, El Serafy derives a simple formula for depletion. In the next section it is shown that, by assuming a geometric path for expected future receipts, an alternative but equally simple depletion formula - see equation (52) - can be derived. The focus here, however, is on comparing 
the relative magnitudes of $\Delta E_{t+1} G N P_{t}, \Delta E_{t+1} N N P_{t}$ and $\Delta N N P_{t}^{H S}$. The assumption of a geometric path for expected future receipts proves very useful here as well. ${ }^{17}$

If expectations of future receipts follow a geometric path, this means that

$$
E_{s} R_{\tau}=\alpha^{\tau-s+1} R_{s-1} \forall \tau \geq s .
$$

Although this specification may seem restrictive, it is probably sufficient for most cases. Given the huge amount of uncertainty over the future price of oil, the expected path of future receipts is unlikely to be very elaborate.

A direct consequence of (32) and (39) is that $E_{t} V_{t}$ and $E_{t+1} V_{t}$ reduce to geometric progressions which converge as long as $\alpha<(1+r)$.

$$
\begin{gathered}
E_{t} V_{t}=\frac{\alpha R_{t-1}}{1+r-\alpha} \\
E_{t+1} V_{t}=\frac{R_{t}}{1+r-\alpha}
\end{gathered}
$$

More generally,

$$
E_{s} V_{t}=\sum_{\tau=t}^{s-1}\left\{\left(\frac{1}{1+r}\right)^{\tau-t+1} R_{\tau}\right\}+\left(\frac{\alpha}{1+r-\alpha}\right)\left(\frac{1}{1+r}\right)^{s-t} R_{s-1} .
$$

Combining (40) and (41), it follows that the unexpected capital gain, $U_{(t, t+1)} G_{t}$, simplifies to

$$
U_{(t, t+1)} G_{t}=E_{t+1} V_{t}-E_{t} V_{t}=\left(\frac{R_{t}-\alpha R_{t-1}}{1+r-\alpha}\right) .
$$

Now, substituting (39) and (43) into (33) and (34), respectively, it follows that

$$
\begin{aligned}
& \Delta E_{t+1} D_{t}=\left(\frac{1-\alpha}{1+r-\alpha}\right)\left(R_{t}-\alpha R_{t-1}\right), \\
& \Delta D_{t}^{H S}=-\left(\frac{\alpha}{1+r-\alpha}\right)\left(R_{t}-\alpha R_{t-1}\right) .
\end{aligned}
$$

A comparison of (44) with (45) reveals that, when $\alpha$ is less than one, $\Delta E_{t+1} D_{t}$ and $\Delta D_{t}^{H S}$ have opposite signs. Therefore, if $R_{t}>\alpha R_{t-1}$, as is likely for an oil exporting

\footnotetext{
${ }^{17}$ This assumption has also been widely used in the capital theory literature, where it is often assumed that the receipts earned on an asset decline geometrically [see Jorgenson (1963) and Jorgenson, Hunter and Nadiri (1970).]
} 
country when the price of oil rises unexpectedly, then depletion falls according to $D_{t}^{H S}$, but rises according to $E_{t+1} D_{t} . \Delta D_{t}^{H S}<0$ because the value of the stock of oil has risen. Conversely, $\Delta E_{t+1} D_{t}>0$ because the value of the oil being extracted has now increased (assuming the rate of extraction does not fall). $\Delta E_{t+1} G N P_{t}$ equals the full amount of the increase in receipts, while $\Delta E_{t+1} N N P_{t}$ equals only the interest earned on the increased valuation of the stock. The rise in GNP is larger than the rise in NNP, and hence the gap between GNP and NNP (i.e., depletion) must have risen.

Substituting (39) and (43) into (37) and (38) generates the following formulae for NNP:

$$
\begin{gathered}
\Delta E_{t+1} N N P_{t}=\left(\frac{r}{1+r-\alpha}\right)\left(R_{t}-\alpha R_{t-1}\right), \\
\Delta N N P_{t}^{H S}=\left(\frac{1+r}{1+r-\alpha}\right)\left(R_{t}-\alpha R_{t-1}\right) .
\end{gathered}
$$

Finally, substituting (39) into (31), we obtain that

$$
\Delta E_{t+1} G N P_{t}=G N P_{t}-E_{t} G N P_{t}=R_{t}-\alpha R_{t-1}
$$

A comparison of (46), (47) and (48) reveals that

$$
\begin{gathered}
0<\alpha<1 \Rightarrow\left|\Delta E_{t+1} N N P_{t}\right|<\left|\Delta E_{t+1} G N P_{t}\right|<\left|\Delta N N P_{t}^{H S}\right|, \\
\alpha=1 \Rightarrow\left|\Delta E_{t+1} N N P_{t}\right|=\left|\Delta E_{t+1} G N P_{t}\right|<\left|\Delta N N P_{t}^{H S}\right|, \\
1<\alpha<1+r \Rightarrow\left|\Delta E_{t+1} G N P_{t}\right|<\left|\Delta E_{t+1} N N P_{t}\right|<\left|\Delta N N P_{t}^{H S}\right| .
\end{gathered}
$$

Therefore, for all permissible values of $\alpha$, it follows from (49), (50) and (51) that $N N P_{t}^{H S}$ is more volatile than both $G N P_{t}$ and $E_{t+1} N N P_{t}$ in period $t$. (The geometric progressions do not converge if $\alpha \geq 1+r$.) Which is more volatile of $G N P_{t}$ and $E_{t+1} N N P_{t}$ depends on the value of $\alpha$. If as in (49) $\alpha<1$, then $E_{t+1} N N P_{t}$ is less volatile than $G N P_{t}$, while if as in (51), $1<\alpha<1+r$, then this result is reversed. For nonrenewable resources we might expect $\alpha$ to be very slightly less than one, since the stock of nonrenewable resources is finite, and hence the amount extracted must eventually decline. Also, rising costs of extraction, as the more profitable deposits are exhausted, 
and increased international competition may cause receipts to decline. Technological progress, however, may prevent this from happening. Indeed, the declining long run real price trend of practically all nonrenewable resources [see Adelman (1990)] is probably attributable to a combination of technological progress and increased international competition. It is less clear what has happened to receipts. Irrespective of the exact value of $\alpha$, as long as it is close to one, this implies that, contrary to the results of most empirical studies, NNP should not be systematically more volatile than GNP.

\section{The Depletion of North Sea Oil and its Impact on British NNP}

This section applies the theoretical framework developed in the previous sections to the depletion of British North Sea Oil fields between 1976 and 1995. In particular, the sensitivity of measured depletion and NNP to the method of measurement is examined. Three sets of NNP estimates are provided: $N N P_{t}^{H S}, E_{t+1} N N P_{t}$ and $E_{96} N N P_{t}$.

It should be emphasized that the empirical results obtained here are illustrative. No attempt has been made to estimate the stock of oil reserves, and the rate at which this stock is extracted. Rather, given that income, correctly defined, is a forward-looking concept, our emphasis is on modelling expectations of future receipts. It is assumed that, in each period, receipts are expected to follow a geometric path. The expected path is updated each period as new information becomes available. Beliefs about the sustainability of current rates of extraction, relative to known reserves, are captured by the parameter $\alpha$ in the geometric progression. Although this formulation is clearly a simplification on reality, given the huge amount of uncertainty regarding the future path of the price of oil, the stock of oil in situ and the cost of extracting it, it seems unlikely that expectations of future receipts can get very much more precise than this. Therefore, the results obtained here are at least indicative of the results that would be obtained in a more detailed comparison.

A similar exercise was previously undertaken by Aslaksen et al. (1990) for Norway over the period 1973 to 1989, with the important difference that they focused on compar- 
isons between ex ante income, $E_{t} N N P_{t}$ and a measure that includes unexpected capital gains (i.e., Haig-Simons income). In contrast, we compare ex post income, $E_{t+1} N N P_{t}$, with Haig-Simons income. This distinction is important since ex post and Haig-Simons income are computed based on the same information, while ex ante and Haig-Simons income are not. Furthermore, income in a national accounts context cannot be measured until the end of the accounting period. This is why the relevant comparison is between ex post and Haig-Simons income. Aslaksen et al. also differs from our paper in the approach used to estimate each income concept and unexpected capital gains.

The North Sea Oil data are shown in Table 1. The quantity of crude oil extracted, $q_{t}^{O}$, is measured in millions of tonnes, and the total oil revenue, $T R_{t}^{O}$, in millions of 1990 pounds. The price index, $p_{t}^{O}$, is obtained implicitly as the ratio of total revenue to quantity extracted. Hence the price index depicts the average price of a tonne of crude oil in 1990 pounds. The quantity of natural gas extracted, $q_{t}^{G}$, is measured in billions of cubic metres, and total gas revenue, $T R_{t}^{G}$, in millions of 1990 pounds. The price index, $p_{t}^{G}$, is again obtained implicitly and depicts the average price of a thousand cubic metres in 1990 pounds. The total revenue, $T R_{t}$, is the total revenue obtained from oil, gas, and other sources. Hence $T R_{t}$ exceeds slightly the sum of $T R_{t}^{O}$ and $T R_{t}^{G}$. The total cost, $T C_{t}$, consists of operating costs for both oil and gas. The receipt, $R_{t}$, is the difference between $T R_{t}$ and $T C_{t}$, and is measured in millions of 1990 pounds. ${ }^{18}$ Investment, $I_{t}$,

\footnotetext{
${ }^{18}$ All quantity, revenue, and cost data were obtained from various issues of the Digest of United Kingdom Energy Statistics, published by the Department of Trade and Industry. For example, in the 1996 issue, revenue and cost data are given in Table 36 on page 84, while extraction data are given in Table 29, page 75. Data on rates of extraction before 1976 are also available in the Digest of United Kingdom Energy Statistics in Table 38 of the 1979 issue. Although offshore production of crude oil only started in 1975, the extraction of onshore crude oil started in the 1960s. From 1975 onwards, onshore extraction is insignificant compared with offshore extraction. Gas revenue data for 1975 are obtained from Johnson (1978), Table 3.4, page 90. Oil revenue for 1975 is obtained by multiplying the price of crude oil by the quantity extracted. The 1975 price data are taken from Allsopp and Rhys (1989), Table 19.2, page 380. Finally, the cost data for 1975 are taken from Johnson (1978), Table 5.3, page 157. All the revenue, cost and price data were converted into 1990 pounds using the GDP
} 
equals total expenditure on development and exploration. Finally, $K_{t}$ is the value of the total capital stock. It is computed assuming a fixed rate of depreciation, $\delta$, of $6 \%$ per year. ${ }^{19}$ Therefore, $K_{t+1}=(1-\delta) K_{t}+I_{t}$.

\section{Insert Table 1 Here}

Table 2 shows estimates of depreciation, depletion and NNP. As discussed above, the rate of depreciation on the capital stock of the oil and gas industry is assumed to be $6 \%$. Hence depreciation is given by $\delta K_{t}$ where $\delta=0.06$. Three different formulae, however, are used to compute depletion. These are Haig-Simons's depletion, $D_{t}^{H S}$ defined in (30), and the generalized-Hicksian depletion formula defined in (28) for the cases where $s=t+1$ and $s=1996$, respectively (i.e., $E_{t+1} D_{t}$ and $E_{96} D_{t}$ ). Given the additional assumptions that real interest rates are fixed and future receipts are expected to follow a geometric path, these three depletion formulae reduce to the expressions stated in (52), (53) and (54).

$$
\begin{gathered}
E_{t+1} D_{t}=E_{t+1} V_{t}-E_{t+1} V_{t+1}=\left(\frac{1}{1+r-\alpha}\right) R_{t}-\left(\frac{\alpha}{1+r-\alpha}\right) R_{t}=\left(\frac{1-\alpha}{1+r-\alpha}\right) R_{t} \\
D_{t}^{H S}=E_{t} V_{t}-E_{t+1} V_{t+1}=\left(\frac{\alpha}{1+r-\alpha}\right) R_{t-1}-\left(\frac{\alpha}{1+r-\alpha}\right) R_{t} \\
=\left(\frac{\alpha}{1+r-\alpha}\right)\left(R_{t-1}-R_{t}\right) \\
E_{s} D_{t}=E_{s} V_{t}-E_{s} V_{t+1}=R_{t}-r E_{s} V_{t} \\
=R_{t}-r\left\{\sum_{\tau=t}^{s-1}\left[\left(\frac{1}{1+r}\right)^{\tau-t+1} R_{\tau}\right]-\left(\frac{r \alpha}{1+r-\alpha}\right)\left(\frac{1}{1+r}\right)^{s-t} R_{s-1}\right\} .
\end{gathered}
$$

deflator in the United Kingdom National Accounts (the Blue Book), Table 1.1, on pages 24 and 25 of the 1997 issue, and pages 10 and 11 of the 1990 issue.

${ }^{19}$ This is the approximate average rate of depreciation of the capital stock in the mining and quarrying category (which includes oil and gas) in the United Kingdom National Accounts (Blue Book, 1997), published by the Office for National Statistics. Capital consumption by industry group is given in Table 14.2, p. 162, while the gross capital stock by industry group is given in Table 14.8, p. 167. The ratio of capital consumption to the gross capital stock is close to 0.06 for all the years in the tables. 
As noted earlier, the depletion formula in (52) is a simple alternative to the one proposed by El Serafy (1989). El Serafy assumes constant receipts for a finite number of periods after which the resource is exhausted, while equation (52) assumes a geometric path for expected future receipts. Expectations are updated each period. Which assumption is preferable, if either, must be judged on a case by case basis.

Returning to equations (52), (53) and (54), by specifying values for $\alpha$ and $r$, depletion can now be computed using the information in Table 1. Estimates of NNP are then obtained by deducting depreciation and depletion from GNP. Since the focus here is on the impact of North Sea Oil on NNP, all other sources of depreciation and depletion in Great Britain are ignored. Three different sets of NNP estimates are derived corresponding to each of the three sets of depletion estimates. The results in Table 2 are obtained assuming that $r=0.05$ and $\alpha=1$, while in Table 3, corresponding estimates are obtained for the case where $r=0.05$ and $\alpha=0.95$.

\section{Insert Table 2 Here}

\section{Insert Table 3 Here}

It is noticeable that the first five observations of $E_{96} D_{t}$ in Table 2 and the first four in Table 3 are all negative. This is an example of negative depletion. It arises because rents in the mid 1970s are much lower than rents in the 1980s. Hence as we move forward in time, the higher rents in the 1980s are discounted less heavily, thus causing the net present value of the stock of oil to rise, even though some oil has been extracted. A second interesting feature in Table 2 is that the depletion estimates for $E_{t+1} D_{t}$ in Table 2 all equal zero. This is because when rents are expected to remain constant (i.e., $\alpha=1$ ) the expected value of the resource at two different points in time, evaluated at the same point in time, must be the same.

The NNP and GNP series from Tables 2 and 3 are graphed, respectively, in Figures 1 and 2. As discussed above, when $\alpha=1$, it follows that $E_{t+1} D_{t}=0$, and hence $E_{t+1} N N P_{t}=G N P-\delta K_{t}$. The volatility of $N N P_{t}^{H S}$, however, is striking in Figure 1. Clearly, in this case $N N P_{t}^{H S}$ is completely useless for policy purposes. In Figure 2, 
$N N P_{t}^{H S}$ is less volatile, since $\alpha$ is smaller. In fact, from (53) it can be seen that as $\alpha$ tends to zero, $D_{t}^{H S}$ does likewise, and hence $N N P_{t}^{H S}$ converges on $G N P_{t}-\delta K_{t}$. This, however, is just a result of the fact that when $\alpha=0, E_{t} V_{t}$ and $E_{t+1} V_{t+1}$ both also equal zero. Clearly, the assumption of geometrically declining receipts becomes untenable when $\alpha$ is too far below one, unless the resource in question has already been almost completely depleted. Even in Figure 2, $N N P_{t}^{H S}$ is too volatile to be of much use for policy purposes.

\section{Insert Figure 1 Here}

\section{Insert Figure 2 Here}

The volatility of $N N P_{t}^{H S}$ is also dependent on the interest rate $r$. In particular, as $r$ falls, $N N P_{t}^{H S}$ becomes even more volatile. For example, when $r=0.01$ and $\alpha=1$ (not shown in the Tables), $N N P_{t}^{H S}$ actually becomes negative in 1986, as a result of the collapse in the price of oil.

The best measure of NNP in both Tables 2 and 3 is provided by the $E_{96} N N P_{t}$ series, since it makes use of the most information, although it suffers from the disadvantage that it can only be calculated retrospectively in 1996. According to the $E_{96} N N P_{t}$ series, most of the depletion of North Sea Oil occurred between 1980 and 1985. This is because this is the period during which oil prices peaked, and hence receipts were highest.

It is also interesting to consider the impact of North Sea Oil on Britain's average growth rate between 1976 and 1995. The average annual growth rate of GNP over this period, $g(G N P)$, expressed as a percentage, is calculated as follows:

$$
g(G N P)=100\left\{\left(\frac{G N P_{1995}}{G N P_{1976}}\right)^{1 / 19}-1\right\}
$$

Average growth rates for NNP are calculated in an analogous manner. The results are shown in Table 4. A comparison of $g\left(G N P_{t}\right)$ and $g\left(E_{96} N N P_{t}\right)$ reveals that accounting for the depletion of North Sea Oil reduces the average annual real growth rate between 1976 and 1995 from $2.09 \%$ to about $1.93 \%$. Although this may sound small, at its peak in 1984 annual depletion of North Sea Oil equalled about 20 billion 1990 pounds. Table 
4 also shows the impact of the large fall in the price of oil in 1986 on measured growth in 1985/6. According to the $N N P_{t}^{H S}$ formula, Britain experienced a huge fall in NNP. In contrast, according to the $E_{t+1} N N P_{t}$ and $E_{96} N N P_{t}$ formulae, NNP actually rose faster during this period than GNP. This is because, once the price of oil collapsed, North Sea Oil revenue and depletion did likewise. Therefore, the gap between GNP and NNP was reduced, i.e., NNP grew faster than GNP.

\section{Insert Table 4 Here}

\section{The Depletion of Oil and its Impact on Indonesian NDP}

We conclude by comparing the Net Domestic Product (NDP) series obtained by Repetto et al. (1989) for Indonesia between 1971 and 1984 with the NDP series obtained using the depletion formulae $E_{t+1} D_{t}$ and $E_{85} D_{t}$ defined in (28). Repetto et al. consider the impact of depletion of petroleum, forestry, and soil on the sustainability of growth in Indonesia. Here, however, we will focus just on the depletion of petroleum. Repetto et al. compute petroleum depletion using the Haig-Simons formula, $D_{t}^{H S}$, defined in (30). The $G D P_{t}$ and $D_{t}^{H S}$ series shown in Table 5 are obtained from Repetto et al.'s Table I.2. The petroleum rents, $R_{t}$, are taken from Table II.4. The $R_{t}$ data in Table II. 4 are in current millions of US dollars. To obtain the $R_{t}$ series in Table 5 , it was first necessary to convert the data into Indonesian rupiah, and then convert them into 1973 rupiah using the Indonesian GDP deflator. The $E_{t+1} D_{t}$ and $E_{85} D_{t}$ series are derived directly from the $R_{t}$ data using equation (54) with $(r=0.05, \alpha=0.95)$. All three NDP series in Table 5 are obtained by subtracting their respective depletion data from GDP. $N D P_{t}^{H S}$ denotes the NDP series, adjusted for depletion of petroleum only, generated by Repetto et al.

Insert Table 5 Here

\section{Insert Figure 3 Here}

GDP and the three NDP series are graphed in Figure 3. The most striking feature of Figure 3 is the huge spike in the $N D P_{t}^{H S}$ series in 1974. Repetto et al. attribute 
this to changes in the US tax law and Indonesian contracts favorable to exploration activities, which led to a sharp increase in reported reserves. Irrespective of its precise cause, the spike has little if any bearing on the sustainability of growth in Indonesia. In contrast, the NDP series, $E_{85} N D P_{t}$, actually falls slightly in 1974 , while $E_{t+1} N D P_{t}$ rises only slightly. The $E_{t+1} N D P_{t}$ and $E_{t+1} N D P_{t}$ series provide more useful guides to the sustainability of the Indonesian economy than $N D P_{t}^{H S}$. The years 1971-3 were characterized by negative depletion, as oil production started to increase from an initially lower level. After 1979, however, Indonesia has experienced depletion in the order of 1000 billion rupiah each year. The average growth rate of NDP also differs significantly depending on which formula is used. The average annual growth rate of $E_{85} N D P_{t}$ is $5.30 \%$, compared with $3.99 \%$ for $N D P_{t}^{H S}, 6.67 \%$ for $E_{t+1} N D P_{t}$ and $7.10 \%$ for $G D P_{t}$. These results, like Table 4, illustrate that there is no particular problem of bias in HaigSimons income estimates over a reasonably long series of observations. The problem arises in the year to year comparisons which can be excessively volatile and seriously misleading with regard to sustainability.

\section{Conclusion}

The deficiencies of GNP as a measure of economic performance are widely recognized. NNP, if broadly defined to include depletion of the natural capital stock, provides potentially a much better yardstick by which to evaluate the performance of governments and countries. However, its use in practice has been severely undermined by its apparent volatility. It is shown here that the observed volatility in NNP is a direct consequence of the incorrect treatment of unexpected capital gains, which breaks the link between NNP and sustainability. When unexpected capital gains are handled correctly, NNP is no more volatile than GNP. Unfortunately, this requires the modelling of expected future receipts from natural assets such as oil fields. This creates its own problems. The empirical estimates of NNP for Great Britain and Indonesia are obtained assuming a geometric path for future receipts. Although these results are only illustrative, they clearly 
demonstrate the importance of the treatment of unexpected capital gains. It is hoped that these findings will encourage governments, national statistical offices, international organizations and journalists to pay more attention to environmentally-adjusted NNP as a useful tool for evaluating the performance of countries over time.

\section{References}

Aaheim, A., and K. Nyborg (1995), "On the Interpretation and Applicability of a Green National Product," Review of Income and Wealth 41(1), 57-71.

Adelman, M. A. (1990), "Mineral Depletion, with Special Reference to Petroleum," Review of Economics and Statistics 72(1), 1-10.

Allsopp, C. and J. Rhys (1989), "The Macroeconomic Impact of North Sea Oil," in The Market for Energy, edited by D. Helm, J. Kay and D. Thompson. Oxford: Clarendon Press, 377-410.

Asheim, G. B. (1996), "Capital Gains and Net National Product in Open Economies," Journal of Public Economics 59, 419-434.

Asheim, G. B. (1997), “Adjusting Green NNP to Measure Sustainability,” Scandinavian Journal of Economics 99(3), 355-370.

Aslaksen, I., K. A. Brekke, T. A. Johnsen and A. Aaheim (1990), "Petroleum Resources and the Management of National Wealth," in Recent Modelling Approaches in Applied Energy Economics, edited by O. Bjerkholt, O. Olsen and J. Vislie. London: Routledge, Chapman \& Hall.

Bartelmus, P., C. Stahmer and J. van Tongeren (1993), "Integrated Environmental and Economic Accounting - A Framework for an SNA Satellite System," in E. Lutz (ed.), Towards Improved Accounting for the Environment, 211-235. Washington, DC: World Bank.

Department of Trade and Industry (1997), Digest of United Kingdom Energy Statistics. London: Government Statistical Service. 
Eisner, R. (1990), "Extended Accounts for National Income and Product: Reply," Journal of Economic Literature 28, 1179-1183.

Eisner, R. (1988), "Extended Accounts for National Income and Product," Journal of Economic Literature 26, 1611-1684.

El Serafy, S. (1989), "The Proper Calculation of Income from Depletable Natural Resources," in Environmental Accounting for Sustainable Development, edited by Y. J. Ahmad, E. El Serafy and P. Lutz. Washington, DC: World Bank.

Friedman, M. (1957), A Theory of the Consumption Function. Princeton: Princeton University Press.

Hartwick, J. (1989), Non-Renewable Resources, Extraction Programs and Markets. Chur, Switzerland: Harwood Academic.

Hartwick, J. and A. Hageman (1993), "Economic Depreciation of Mineral Stocks and the Contribution of El Serafy," in E. Lutz (ed.), Towards Improved Accounting for the Environment, 211-235. Washington, DC: World Bank.

Haig, R. M. (1959), "The Concept of Income: Economic and Legal Aspects," in Readings in the Economics of Taxation, edited by R. A. Musgrave and C. S. Shoup. Homewood, IL: Irwin (Originally Published in 1921), 54-76.

Hicks, J. R. (1946), Value and Capital, Second Edition. Oxford: Oxford University Press.

Hill, R. J., and T. P. Hill (2003), "Expectations, Capital Gains and Income," Economic Inquiry, forthcoming.

Hotelling, H. (1931), "The Economics of Exhaustible Resources," Journal of Political Economy 39(2), 137-175.

Hotelling, H. (1925), "A General Mathematical Theory of Depreciation," Journal of the American Statistical Association, September, 340-353. 
Johnson, C. (1978), North Sea Energy Wealth 1965-1985, Vol. 1. London: The Financial Times Ltd.

Jorgenson, D. W. (1963), "Capital Theory and Investment Behavior," American Economic Review 53, 247-259.

Jorgenson, D. W., J. Hunter and M. Nadiri (1970), "A Comparison of Alternative Econometric Models of Quarterly Investment Behavior," Econometrica 38, 187-212.

Mäler, K.-G. (1991), "National Accounts and Environmental Resources," Environmental and Resource Economics 1, 1-15.

McElroy, M. B. (1976), "Capital Gains and Social Income," Economic Inquiry 14(2), 221-240.

Nordhaus, W. D., and E. C. Kokkelenberg, eds. (1999), Nature's Numbers: Expanding the National Income Accounts to Include the Environment. Washington, D.C.: National Academy Press.

Office for National Statistics (1997), United Kingdom National Accounts - The Blue Book. London: Government Statistical Service.

Pearce, D. W. and G. Atkinson (1995), "Measuring Sustainable Development," in The Handbook of Environmental Economics, edited by D. W. Bromley. Oxford, UK \& Cambridge, USA: Blackwell, 166-181.

Repetto, R., W. McGrath, M. Wells, C. Beer, and F. Rossini (1989), Wasting Assets: Natural Resources in the National Income Accounts. Washington, D.C.: World Resources Institute.

Repetto, R. (1992), "Accounting for Environmental Assets," Scientific American, June, 64-70.

Simons, H. C. (1938), Personal Income Taxation. Chicago: University of Chicago Press.

Solow, R. M. (1974), "Intergenerational Equity and Exhaustible Resources," Review of Economic Studies, Symposium, 29-45. 
System of National Accounts (1993), Brussels/Luxembourg, New York, Paris, Washington, D.C.: Commission of the European Communities, International Monetary Fund, Organisation for Economic Cooperation and Development, United Nations, World Bank,

Thage, B. (1991), "The National Accounts and the Environment," Paper presented at the International Association for Research in Income and Wealth IARIW Special Conference on Environmental Accounting, Baden, Austria, May.

Vincent, J. R., T. Panayotou, and J. M. Hartwick (1997), "Resource Depletion and Sustainability in Small Open Economies," Journal of Environmental Economics and Management 33, 274-286.

Weitzman, M. L. (1976), "On the Welfare Significance of National Product in a Dynamic Economy," Quarterly Journal of Economics 90, 156-162.

Weitzman, M. L. (1997), "Sustainability and Technical Progress," Scandinavian Journal of Economics 99(1), 1-13.

Young, M. (1993), "Natural Resource Accounting: Some Australian Experiences and Observations," in Toward Improved Accounting for the Environment, edited by E. Lutz. Washington, DC: World Bank, 177-183. 
Table 1.- North Sea Oil Data

\begin{tabular}{rrrrrrrrrrrr}
\hline \hline Year & \multicolumn{1}{c}{$q_{t}^{O}$} & \multicolumn{1}{c}{$p_{t}^{O}$} & \multicolumn{1}{c}{$T R_{t}^{O}$} & $q_{t}^{G}$ & $p_{t}^{G}$ & $T R_{t}^{G}$ & $T R_{t}$ & $T C_{t}$ & \multicolumn{1}{c}{$R_{t}$} & $I_{t}$ & $K_{t}$ \\
\hline 1975 & 0.9 & 135.8 & 121 & 36.3 & 19.6 & 710 & 834 & 256 & 578 & 6810 & 7308 \\
1976 & 11.6 & 170.6 & 1985 & 38.4 & 21.3 & 820 & 2939 & 414 & 2526 & 7024 & 13680 \\
1977 & 37.4 & 163.8 & 6128 & 40.3 & 21.9 & 884 & 7149 & 577 & 6572 & 6401 & 19883 \\
1978 & 52.9 & 131.3 & 6947 & 38.5 & 28.1 & 1083 & 8148 & 867 & 7281 & 5711 & 25091 \\
1979 & 76.6 & 161.3 & 12352 & 39.2 & 30.0 & 1179 & 13742 & 1136 & 12606 & 5124 & 29297 \\
1980 & 78.9 & 202.4 & 15976 & 37.3 & 31.8 & 1186 & 17555 & 1330 & 16225 & 5182 & 32663 \\
1981 & 88.0 & 228.5 & 20095 & 37.4 & 37.1 & 1388 & 21893 & 1750 & 20143 & 5708 & 35885 \\
1982 & 100.3 & 215.2 & 21589 & 37.8 & 38.6 & 1462 & 23856 & 2002 & 21854 & 5998 & 39440 \\
1983 & 111.0 & 216.2 & 23995 & 38.7 & 41.8 & 1618 & 26663 & 2173 & 24491 & 5584 & 43072 \\
1984 & 121.3 & 228.1 & 27674 & 38.5 & 46.9 & 1805 & 30749 & 2408 & 28340 & 6272 & 46071 \\
1985 & 122.5 & 204.5 & 25046 & 43.0 & 52.2 & 2244 & 28694 & 2953 & 25741 & 5660 & 49578 \\
1986 & 121.3 & 93.3 & 11310 & 45.3 & 54.0 & 2446 & 14823 & 2721 & 12102 & 4373 & 52263 \\
1987 & 117.7 & 97.7 & 11495 & 47.6 & 50.5 & 2405 & 14976 & 2546 & 12430 & 3461 & 53501 \\
1988 & 109.5 & 73.0 & 7989 & 45.8 & 51.2 & 2345 & 11169 & 2350 & 8818 & 3800 & 53751 \\
1989 & 87.4 & 86.9 & 7592 & 44.8 & 50.5 & 2261 & 10568 & 2479 & 8088 & 4152 & 54326 \\
1990 & 88.0 & 94.2 & 8291 & 49.6 & 47.6 & 2360 & 11326 & 2847 & 8479 & 5082 & 55218 \\
1991 & 86.8 & 81.8 & 7107 & 55.2 & 50.8 & 2802 & 10716 & 3145 & 7571 & 6622 & 56987 \\
1992 & 89.2 & 74.7 & 6664 & 56.0 & 48.4 & 2705 & 10273 & 3018 & 7255 & 6297 & 60190 \\
1993 & 94.0 & 75.0 & 7048 & 65.3 & 47.5 & 3101 & 11209 & 3222 & 7987 & 5126 & 62875 \\
1994 & 119.0 & 64.4 & 7664 & 69.6 & 47.1 & 3280 & 12229 & 3347 & 8881 & 3958 & 64229 \\
1995 & 121.8 & 67.7 & 8250 & 75.5 & 45.8 & 3457 & 13192 & 3298 & 9894 & 4554 & 64333 \\
1996 & 121.8 & 78.9 & 9607 & 89.9 & 47.8 & 4293 & 15514 & 3250 & 12264 & 4430 & 65027 \\
\hline & & & & & & & & & & &
\end{tabular}


Table 2.- Depreciation, Depletion, NNP and GNP in Millions of 1990

Pounds $(r=0.05, \alpha=1)$

\begin{tabular}{rrrrrrrrr}
\hline \hline Year & $\delta K_{t}$ & \multicolumn{1}{c}{$D_{t}^{H S}$} & $E_{t+1} D_{t}$ & $E_{96} D_{t}$ & $N N P_{t}^{H S}$ & $E_{t+1} N N P_{t}$ & $E_{96} N N P_{t}$ & $G N P_{t}$ \\
\hline 1976 & 821 & -38951 & 0 & -9352 & 439228 & 400277 & 409630 & 401098 \\
1977 & 1193 & -80918 & 0 & -5774 & 486200 & 405282 & 411056 & 406475 \\
1978 & 1505 & -14185 & 0 & -5354 & 434555 & 420370 & 425723 & 421875 \\
1979 & 1758 & -106494 & 0 & -297 & 539011 & 432516 & 432813 & 434274 \\
1980 & 1960 & -72390 & 0 & 3308 & 492619 & 420228 & 416920 & 422188 \\
1981 & 2153 & -78353 & 0 & 7391 & 495383 & 417030 & 409639 & 419183 \\
1982 & 2366 & -34220 & 0 & 9472 & 458439 & 424219 & 414747 & 426585 \\
1983 & 2584 & -52738 & 0 & 12582 & 494194 & 441456 & 428873 & 444040 \\
1984 & 2764 & -76994 & 0 & 17061 & 530210 & 453216 & 436155 & 455980 \\
1985 & 2975 & 51996 & 0 & 15314 & 415005 & 467001 & 451687 & 469976 \\
1986 & 3136 & 272775 & 0 & 2441 & 217390 & 490165 & 487724 & 493301 \\
1987 & 3210 & -6565 & 0 & 2892 & 519260 & 512695 & 509803 & 515905 \\
1988 & 3225 & 72236 & 0 & -576 & 466783 & 539019 & 539595 & 542244 \\
1989 & 3260 & 14602 & 0 & -1334 & 534699 & 549300 & 550635 & 552560 \\
1990 & 3313 & -7815 & 0 & -1010 & 556889 & 549074 & 550084 & 552387 \\
1991 & 3419 & 18163 & 0 & -1969 & 518876 & 537039 & 539008 & 540458 \\
1992 & 3611 & 6324 & 0 & -2384 & 530628 & 536953 & 539336 & 540564 \\
1993 & 3773 & -14646 & 0 & -1771 & 561880 & 547234 & 549005 & 551007 \\
1994 & 3854 & -17884 & 0 & -965 & 594964 & 577080 & 578045 & 580934 \\
1995 & 3860 & -20265 & 0 & 0 & 610916 & 590651 & 590651 & 594511 \\
\hline & & & & & & & &
\end{tabular}


Table 3.- Depreciation, Depletion, NNP and GNP in Millions of 1990

Pounds $(r=0.05, \alpha=0.95)$

\begin{tabular}{rrrrrrrrr}
\hline \hline Year & $\delta K_{t}$ & \multicolumn{1}{c}{$D_{t}^{H S}$} & $E_{t+1} D_{t}$ & $E_{96} D_{t}$ & $N N P_{t}^{H S}$ & $E_{t+1} N N P_{t}$ & $E_{96} N N P_{t}$ & $G N P_{t}$ \\
\hline 1976 & 821 & -18502 & 1263 & -7395 & 418779 & 399014 & 407672 & 401098 \\
1977 & 1193 & -38436 & 3286 & -3719 & 443718 & 401996 & 409001 & 406475 \\
1978 & 1505 & -6738 & 3640 & -3195 & 427107 & 416729 & 423565 & 421875 \\
1979 & 1758 & -50585 & 6303 & 1970 & 483101 & 426213 & 430546 & 434274 \\
1980 & 1960 & -34385 & 8113 & 5688 & 454614 & 412116 & 414540 & 422188 \\
1981 & 2153 & -37218 & 10071 & 9890 & 454248 & 406958 & 407140 & 419183 \\
1982 & 2366 & -16255 & 10927 & 12095 & 440473 & 413292 & 412123 & 426585 \\
1983 & 2584 & -25051 & 12245 & 15337 & 466506 & 429210 & 426119 & 444040 \\
1984 & 2764 & -36572 & 14170 & 19954 & 489788 & 439046 & 433262 & 455980 \\
1985 & 2975 & 24698 & 12870 & 18352 & 442303 & 454131 & 448650 & 469976 \\
1986 & 3136 & 129568 & 6051 & 5630 & 360597 & 484114 & 484535 & 493301 \\
1987 & 3210 & -3118 & 6215 & 6240 & 515813 & 506480 & 506455 & 515905 \\
1988 & 3225 & 34312 & 4409 & 2940 & 504707 & 534610 & 536079 & 542244 \\
1989 & 3260 & 6936 & 4044 & 2357 & 542365 & 545256 & 546943 & 552560 \\
1990 & 3313 & -3712 & 4240 & 2866 & 552786 & 544834 & 546208 & 552387 \\
1991 & 3419 & 8627 & 3785 & 2101 & 528411 & 533253 & 534938 & 540458 \\
1992 & 3611 & 3004 & 3627 & 1890 & 533949 & 533325 & 535063 & 540564 \\
1993 & 3773 & -6957 & 3993 & 2717 & 554191 & 543241 & 544518 & 551007 \\
1994 & 3854 & -8495 & 4441 & 3747 & 585575 & 572640 & 573334 & 580934 \\
1995 & 3860 & -9626 & 4947 & 4947 & 600277 & 585704 & 585704 & 594511 \\
\hline
\end{tabular}


Table 4.- Average Annual Real Growth Rates of NNP and GNP

\begin{tabular}{lrrrr}
\hline \hline & $1976 / 95$ & $1976 / 95$ & $1985 / 86$ & $1985 / 86$ \\
& $r=0.05$ & $r=0.05$ & $r=0.05$ & $r=0.05$ \\
& $\alpha=1$ & $\alpha=0.95$ & $\alpha=1$ & $\alpha=0.95$ \\
\hline$g\left(G N P_{t}\right)$ & 2.093 & 2.093 & 4.963 & 4.963 \\
$g\left(N N P_{t}^{H S}\right)$ & 1.752 & 1.913 & -47.618 & -18.473 \\
$g\left(E_{t+1} N N P_{t}\right)$ & 2.069 & 2.041 & 4.960 & 6.602 \\
$g\left(E_{96} N N P_{t}\right)$ & 1.945 & 1.925 & 7.978 & 7.998 \\
\hline
\end{tabular}

Table 5.- Depletion, NDP and GDP in Billions of 1973 Rupiah Between 1971 and $1984\left(E_{85} N D P_{t}\right.$ calculated assuming $\left.r=0.05, \alpha=0.95\right)$

\begin{tabular}{rrrrrrrrr}
\hline \hline & $R_{t}$ & $D_{t}^{H S}$ & $E_{t+1} D_{t}$ & $E_{85} D_{t}$ & $N D P_{t}^{H S}$ & $E_{t+1} N D P_{t}$ & $E_{85} N D P_{t}$ & $G D P_{t}$ \\
\hline 1971 & 274 & -1527 & 137 & -854 & 7072 & 5408 & 6399 & 5545 \\
1972 & 476 & -337 & 238 & -694 & 6404 & 5829 & 6761 & 6067 \\
1973 & 595 & -407 & 298 & -610 & 7160 & 6456 & 7363 & 6753 \\
1974 & 1281 & -3228 & 641 & 46 & 10524 & 6656 & 7250 & 7296 \\
1975 & 1224 & 787 & 612 & -10 & 6844 & 7019 & 7641 & 7631 \\
1976 & 1271 & 187 & 636 & 37 & 7969 & 7521 & 8119 & 8156 \\
1977 & 1446 & 1225 & 723 & 214 & 7657 & 8159 & 8668 & 8882 \\
1978 & 1344 & 1117 & 672 & 123 & 8450 & 8895 & 9444 & 9567 \\
1979 & 1381 & 1200 & 691 & 166 & 8965 & 9475 & 9999 & 10165 \\
1980 & 2161 & 1633 & 1081 & 955 & 9536 & 10089 & 10214 & 11169 \\
1981 & 2505 & 1552 & 1253 & 1347 & 10503 & 10803 & 10708 & 12055 \\
1982 & 1796 & 1158 & 898 & 705 & 11167 & 11427 & 11620 & 12325 \\
1983 & 2113 & 1825 & 1057 & 1057 & 11017 & 11786 & 11785 & 12842 \\
1984 & 2007 & 1765 & 1003 & 1003 & 11755 & 12517 & 12517 & 13520 \\
\hline
\end{tabular}




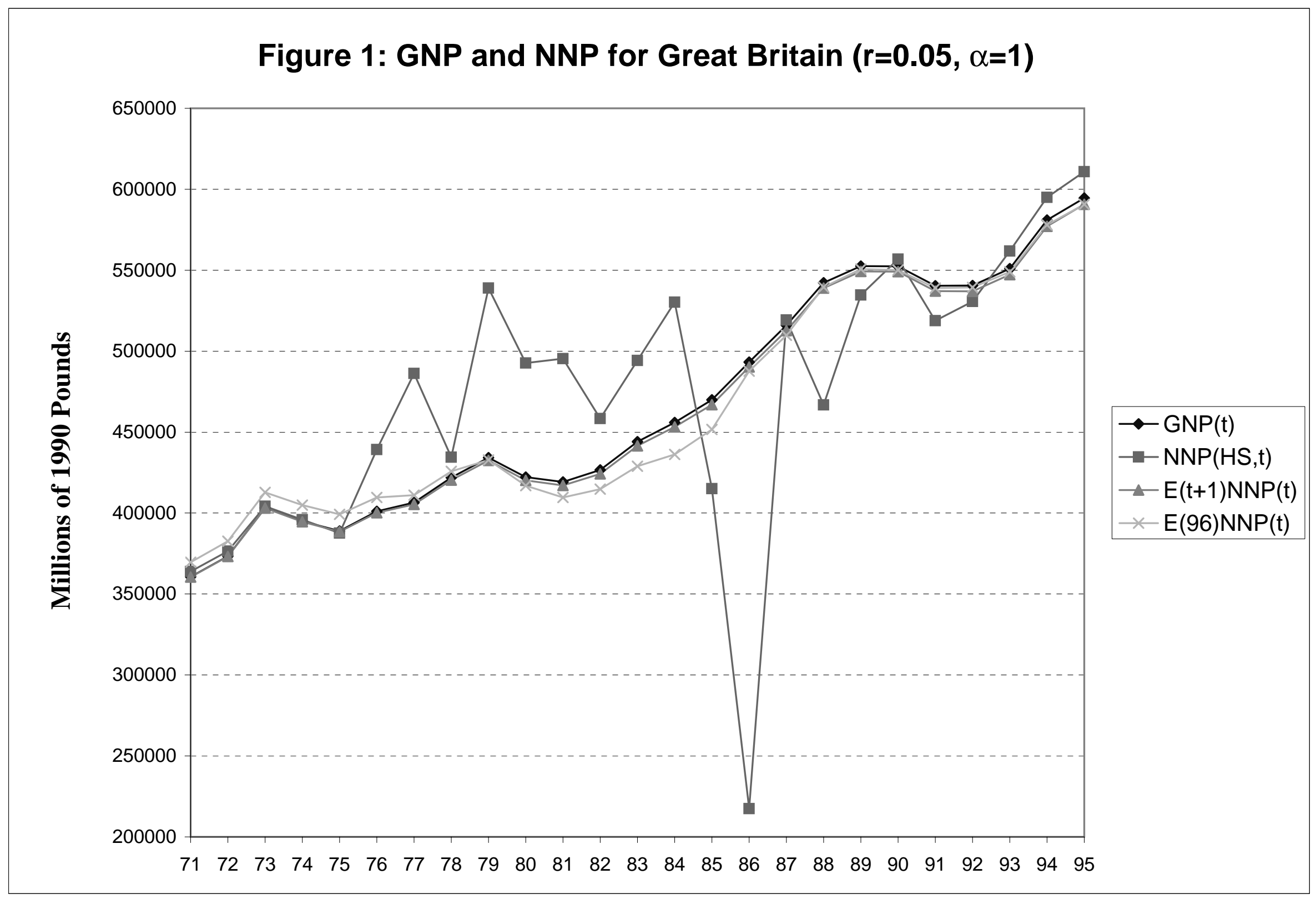




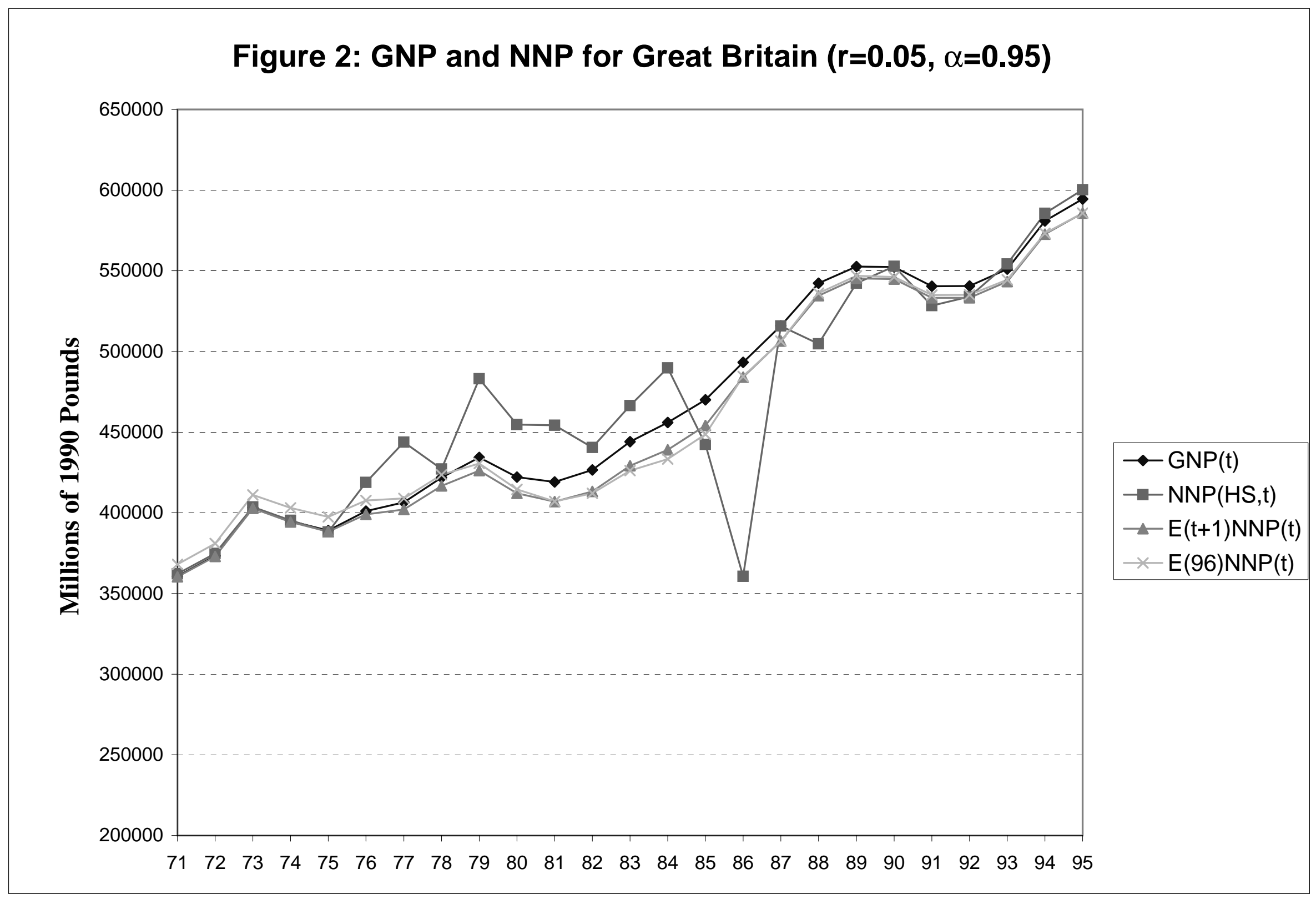




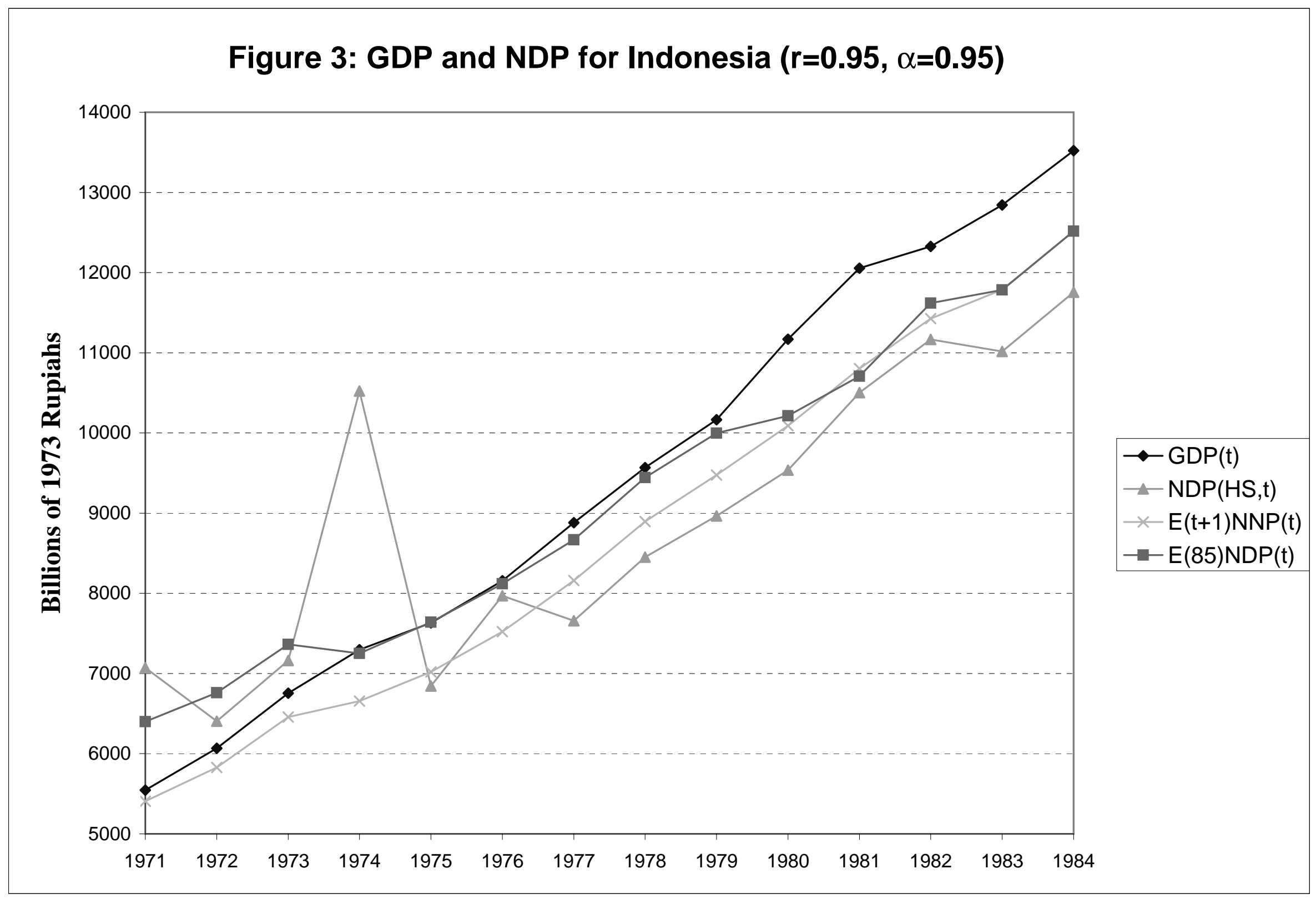

